\title{
CITRA PROFESI PERAWAT MENURUT PERSEPSI MAHASISWA KESEHATAN (FARMASI) DI YOGYAKARTA
}

\author{
Aulia Hanif Fathudin ${ }^{1}$, Elsi Dwi Hapsari²,* \\ ${ }^{1}$ Program Studi Ilmu Keperawatan Fakultas Kedokteran Universitas Gadjah Mada \\ J1. J1. Farmako Sekip Utara, Yogyakarta, 55281, Indonesia \\ ${ }^{2}$ Dosen Program Studi Ilmu Keperawatan Fakultas Kedokteran Universitas Gadjah Mada \\ Jl. Farmako Sekip Utara, Yogyakarta, 55281, Indonesia \\ *)E-mail: elsidh@ugm.ac.id
}

Diterima: Desember 2017, diterbitkan: April 2018

\begin{abstract}
ABSTRAK
Latar Belakang: Citra profesi perawat terbentuk dari adanya kontak antara perawat dengan pasien dan tenaga kesehatan lain. Informasi tentang citra profesi perawat dari mahasiswa calon tenaga kesehatan masih kurang. Citra yang dipersepsikan baik nantinya mendukung kolaborasi dalam pelayanan kesehatan. Tujuan Penelitian: Mengetahui citra profesi perawat yang dipersepsikan oleh mahasiswa farmasi di Yogyakarta. Metode: Penelitian deskriptif kuantitatif dengan pendekatan cross sectional, dilaksanakan di UMY dan UGM pada bulan Februari-Mei 2016. Sampel penelitian adalah mahasiswa farmasi angkatan aktif diambil dengan purposive sampling $(\mathrm{n}=329)$. Penelitian menggunakan instrumen berupa kuesioner modifikasi dari penelitian lain, meliputi citra sikap, perilaku, kinerja, profesi dan pelayanan keperawatan, otonomi dan peran perawat. Analisis data secara univariat yang menggambarkan frekuensi dan persentase respon. Hasil: Citra profesi perawat dipersepsikan positif oleh mahasiswa farmasi (57,4\%). Responden mempersepsikan positif sikap perawat (84,2\%), perilaku perawat $(50,5 \%)$, kinerja perawat $(52,6 \%)$, profesi dan pelayanan keperawatan $(58,1 \%)$. Bagian otonomi dan peran perawat dipersepsikan negatif oleh $51,4 \%$ responden. Diskusi: Citra profesi perawat yang dipersepsikan positif ini dapat dipengaruhi oleh pengetahuan dan pengalaman responden yang baik saat berinteraksi dengan perawat. Sementara persepsi citra yang negatif dapat muncul karena adanya mitos dan miskonsepsi. Kesimpulan: Citra profesi perawat menurut persepsi mahasiswa farmasi tergolong dalam kategori positif. Namun, otonomi/kemandirian perawat masih dinilai rendah dan peran kolaborasi dengan tenaga kesehatan lain belum maksimal. Perawat dalam pelayanannya perlu meningkatkan peran mandiri dan kolaborasi serta semakin menunjukkan profesionalitas sehingga dapat membangun citra baik di masyarakat.
\end{abstract}

Kata Kunci: citra, perawat, mahasiswa, farmasi, persepsi

\section{Image of Nurse Profession Perceived by Health Students (Pharmacy) in Yogyakarta ABSTRACT}

Background: The image of nurse profession is created from contact between nurses with patients and other health professionals. There is only very little information about the image of nurse profession from prospective health professional students. A well-perceived image will later support collaboration in health services. Objective: To identify the image of nurse profession perceived by pharmacy students in Yogyakarta. Methods: This research is quantitative descriptive using cross sectional approach, conducted at UMY and UGM in February 2016-May 2016. The research samples were active pharmacy students taken by using purposive sampling $(n=329)$. The research instrument was modified questionnaires from other research, including attitude, behavior, performance, nursing profession and service, nurse's autonomy and role. Data were analyzed using univariate analysis that described frequency and percentage of responses. Results: The image of nurse profession was perceived positively by pharmacy students (57.4\%). Respondents positively perceived nurse's attitude 
(84.2\%), nurse's behavior (50.5\%), nurse's performance (52.6\%), nursing profession and service (58,1\%). The autonomy and role of nurse were negatively perceived by $51.4 \%$ of respondents. Discussion: The positive image of nursing profession can be influenced by the good knowledge and experience of respondents when interacting with nurses. The negative image perception can arise due to myths and misconceptions. Conclusion: The image of the nurse profession perceived by the pharmacy students can categorized into positive perception. However, the autonomy and role of nurse are still regarded low. Nurses need to improve independent and collaborative nursing services in order to create a more professional image. Keywords: image, nurse, students, pharmacy, perception

\section{LATAR BELAKANG}

Pada tahun 2013 tercatat jumlah perawat di Indonesia sebanyak 288.405 orang. Jumlah ini paling banyak jika dibandingkan dengan jumlah tenaga kesehatan lain (Kementerian Kesehatan Republik Indonesia, 2014). Perawat juga menjadi tenaga kesehatan yang paling sering berhadapan dengan pasien, sehingga rendahnya kualitas pelayanan kesehatan yang ada kadang disalahkan pada perawat dan mengakibatkan citra perawat buruk di masyarakat (Sudarma, 2008). Berdasarkan hasil penelitian Yuda, Handoyo, \& Asti (2010), siswa perempuan kelas XII di Kabupaten Kebumen masih menganggap perawat subordinat dokter dan profesi ners tidak setara dengan dokter. Pada penelitian Thompson et al. (2011), masyarakat London, Inggris mempersepsikan perawat sebagai pekerjaan yang patut dihargai dan dikagumi namun tidak menjadi pilihan karier bagi diri mereka ataupun kerabat dekatnya. Sementara pada penelitian Samaniego \& Carcamo (2013) dokter dan tenaga kesehatan lain menganggap perawat mengenali fungsi spesifiknya dan memiliki antusiasme yang baik untuk belajar dan memperbaiki diri. Namun, pada aspek lain perawat tidak selalu melakukan yang direkomendasikan dan tidak memperhatikan indikasi medis.

Peningkatan prevalensi penyakit kronis dan perkembangan fokus pelayanan kesehatan pada pasien membuat perlunya koordinasi perawatan yang melibatkan pelayanan kesehatan profesional dan pendekatan interdisiplin (American College of Clinical Pharmacy (ACCP) White Paper,

2009). Pemerintah Indonesia melalui kegiatan Health Professional Education Quality (HPEQ) yang dimulai sejak tahun 2010, melakukan inisiasi program Interprofessional Education dan Collaborative Practice guna menumbuhkembangkan dan memperkokoh nilai-nilai kolaborasi antar profesi yang dimulai sejak masa pendidikan (Direktorat Jenderal Pendidikan Tinggi Kementerian Pendidikan dan Kebudayaan, 2014).

Pelaksanaan kolaborasi antar profesi kesehatan dipengaruhi oleh banyak faktor yang dapat mendukung dan menghambat, salah satunya stereotype. Pada berbagai penelitian disebutkan stereotype yang negatif dari masing-masing profesi dan antar profesi dapat menghambat interaksi dan komunikasi (Cook \& Stoecker, 2014). Adanya kontak pribadi masyarakat dengan perawat dan kontak perawat dengan tim kesehatan di area kerja membentuk citra perawat menjadi positif atau negatif (The Image of Nursing, 2011). Berdasar hasil penelitian Wilbur \& Kelly (2015), mahasiswa farmasi menyatakan sikap positif terhadap nilai kontribusi keperawatan dalam perawatan pasien. Perawat menjadi sarana untuk mengumpulkan informasi pasien.

Penelitian mengenai citra perawat di Indonesia masih jarang dilakukan dan biasanya menggunakan responden pasien atau masyarakat umum. Berdasarkan halhal yang telah disebutkan di atas peneliti bermaksud melakukan penelitian mengenai citra profesi perawat pada mahasiswa kesehatan, dalam hal ini khususnya 
mahasiswa farmasi di Yogyakarta. Sehingga dapat diketahui citra profesi perawat dari persepsi mahasiswa farmasi di Yogyakarta.

\section{METODE}

Penelitian ini merupakan penelitian deskriptif kuantitatif yang menggambarkan citra profesi perawat menurut persepsi mahasiswa farmasi di Yogyakarta. Populasi penelitian adalah semua mahasiswa farmasi angkatan aktif di Universitas Muhammadiyah Yogyakarta (UMY) dan Universitas Gadjah Mada Yogyakarta (UGM). Pengambilan sampel menggunakan teknik purposive sampling dengan kriteria inklusi: 1) Mahasiswa farmasi yang terdaftar aktif di UMY dan UGM, 2) Mahasiswa farmasi program sarjana (S1) yang bersedia menjadi responden penelitian.

Peneliti menggunakan satu instrumen dalam penelitian ini yaitu kuesioner untuk persepsi mahasiswa kesehatan (farmasi) tentang citra profesi perawat. Kuesioner dibuat dan dimodifikasi oleh peneliti dari kuesioner penelitian lain, yakni penelitian Desiana (2012) mengenai "Hubungan antara Persepsi Pelajar Sekolah Menengah Atas (SMA) Kelas XII dengan Minat Melanjutkan Pendidikan di Bidang Keperawatan", penelitian Handoyo, Kamaluddin, \& Ekowati (2006) mengenai "Persepsi Siswa SMA terhadap Profesi dan Pendidikan Sarjana Keperawatan", dan penelitian Meiring \& Wyk (2013) mengenai "Citra Perawat dan Keperawatan seperti yang dipersepsikan Masyarakat Afrika Selatan".

Kuesioner berupa pernyataan dengan skala likert dan pilihan jawaban tunggal. Kriteria nilai dalam skala likert untuk pernyataan positif adalah Sangat Setuju (SS) $=4$, Setuju $(S)=3$, Tidak Setuju $(T S)=2$, dan Sangat Tidak Setuju (STS) $=1$. Sedangkan untuk pernyataan negatif kriteria nilainya adalah Sangat Setuju (SS) $=1$, Setuju $(S)=2$, Tidak Setuju $(T S)=3$, dan Sangat Tidak
Setuju (STS)=4. Interpretasi hasil penelitian menggunakan hitungan skor responden yang kemudian dikategorikan berdasar pemusatan data (nilai mean atau median). Kategori positif total skor $\geq$ mean/median data, kategori negatif total skor $<$ mean/median. Sebelum digunakan, kuesioner diuji validitas dan reliabilitasnya pada 40 responden mahasiswa farmasi di UGM. Uji validitas dengan korelasi pearson product moment didapatkan hasil 38 item valid. Uji reliabilitas menunjukkan hasil nilai $\alpha>0,7 \quad(\alpha=0,944)$ sehingga kuesioner terbukti reliabel.

Pengambilan data dimulai dengan melakukan perekrutan responden dan asisten peneliti setelah mendapatkan ethical clearance dari Komisi Etik Fakultas Kedokteran Universitas Gadjah Mada dan izin penelitian. Pengumpulan data dilaksanakan mulai bulan Februari-Mei 2016 di Program Studi Farmasi Fakultas Kedokteran dan IImu Kesehatan UMY dan Fakultas Farmasi UGM pada hari yang berbeda menyesuaikan jadwal akademik masing-masing kampus.

Peneliti memberikan lembar penjelasan dan persetujuan penelitian (informed consent) untuk menghormati hak dan kewajiban dari responden penelitian. Responden yang terlibat dalam penelitian secara suka rela dan bersedia mengisi kuesioner sesuai dengan tata caranya. Data yang dikumpulkan sejumlah 358 tetapi 29 data tidak lengkap sehingga total data yang terkumpul sebanyak 329.

Peneliti memulai analisis data dengan memeriksa kelengkapan kuesioner yang telah diisi oleh reponden. Kuesioner yang datanya tidak terisi lengkap dianggap gugur (drop out) dan dipisahkan dari kuesioner lainnya. Kemudian data dimasukkan ke dalam program excel dan selanjutnya dianalisis dengan program statistik. Data yang diperoleh berdistribusi tidak normal dan berupa data kategorik nominal dan 
ordinal. Beberapa hal yang menjadi fokus penelitian adalah mengenai frekuensi dan persentase jumlah respon. Analisis data penelitian berupa statistik deskriptif/univariat, menunjukkan karakteristik responden dan persepsi responden terhadap citra profesi perawat.

Tabel 1. Statistik Hasil Citra Profesi Perawat

\begin{tabular}{lc}
\hline Statistik Nilai & Hasil \\
\hline Frekuensi & 329 \\
Median & 124 \\
Skewness & 0,73 \\
Standard Error of Skewness & 0,13 \\
Kurtosis & 0,43 \\
Standard Error of Kurtosis & 0,27 \\
Sum & 41823 \\
\hline
\end{tabular}

Tabel 1 menunjukkan besar nilai median 124; skewness 0,73; dan standard error of skewness 0,13. Berdasarkan parameter skewness hasil bagi nilai skewness dan standard error of skewness 5,62 (di luar -2 dan 2) data tidak terdistribusi normal. Pengkategorian citra kemudian ditetapkan dengan nilai median, dikatakan positif jika total skor $\geq 124$.

\section{HASIL}

\section{Karakteristik Responden}

Responden penelitian berjumlah 329 orang yang merupakan mahasiswa farmasi dari dua perguruan tinggi, yakni UMY dan UGM. Responden adalah mahasiswa angkatan aktif $(2012,2013,2014,2015)$ dengan rentang usia 16 hingga 25 tahun. Mayoritas responden $(84,8 \%)$ berjenis kelamin perempuan dan kebanyakan berasal dari Jawa Tengah dan DI Yogyakarta. Sebanyak 142 responden memiliki pengalaman dirawat di rumah sakit dan 187 responden memiliki kerabat seorang perawat. 
Tabel 2. Distribusi Frekuensi Responden berdasarkan Karakteristik Dasar ( $n=329)$

\begin{tabular}{lll}
\hline Karakteristik & Jumlah responden $(\mathrm{n})$ & Persentase $(\%)$ \\
\hline Usia (tahun) & & \\
16-17 & 8 & 2,4 \\
18-25 & 321 & 97,6 \\
Jenis Kelamin & & \\
Laki-laki & 50 & 15,2 \\
Perempuan & 279 & 84,8 \\
Instansi & & \\
UGM & 180 & 54,7 \\
UMY & 149 & 45,3 \\
Angkatan & & \\
2012 & 74 & 22,5 \\
2013 & 77 & 23,4 \\
2014 & 70 & 21,3 \\
2015 & 108 & 32,8 \\
Pengalaman dirawat di & & \\
RS & & \\
Pernah & 142 & 43,2 \\
Tidak Pernah & 187 & 56,8 \\
Kekerabatan dengan & & \\
perawat & & 56,8 \\
Ada & 187 & \\
Tidak ada & 142 & \\
\hline Sumber Data : Primer $(2016)$ & \\
\hline
\end{tabular}

\section{Citra Profesi Perawat}

Dari hasil pengolahan data $(n=329)$ menggunakan program komputer didapatkan besar nilai mean 127,12; median 124; skewness 0,73; dan standard error of skewness 0,13.

Tabel 3. Distribusi Frekuensi Responden berdasarkan Pengalaman Interaksi dengan Perawat dan Persepsi terhadap Citra Profesi Perawat $(n=329)$

\begin{tabular}{lllll}
\hline Karakteristik & \multicolumn{2}{c}{ Citra Positif } & \multicolumn{2}{c}{ Citra Negatif } \\
& $(\mathrm{n})$ & $(\%)$ & $(\mathrm{n})$ & $(\%)$ \\
\hline Pernah dirawat, ada kerabat perawat & 60 & 18,2 & 38 & 11,5 \\
Pernah dirawat, tidak ada kerabat perawat & 25 & 7,6 & 19 & 5,8 \\
Tidak pernah dirawat, ada kerabat perawat & 47 & 14,3 & 42 & 12,8 \\
Tidak pernah dirawat, tidak ada kerabat perawat & 57 & 17,3 & 41 & 12,5 \\
\hline
\end{tabular}

Sumber Data : Primer (2016) 
Berdasarkan Tabel 3, diketahui bahwa 189 responden mempersepsikan citra profesi perawat positif sebanyak 85 responden pernah dirawat dan 104 responden tidak pernah dirawat. Sementara 140 responden mempersepsikan citra profesi perawat negatif dengan 57 responden pernah dirawat dan 83 responden tidak pernah dirawat.

Selain dinilai secara umum, citra profesi perawat juga dinilai per bagian (sikap, perilaku, kinerja perawat, profesi dan pelayanan keperawatan, otonomi dan peran perawat). Pada citra profesi perawat yang dipersepsikan per bagian ini, diketahui distribusi data tidak normal (menggunakan parameter skewness). Hasil bagi antara nilai skewness dengan standard error of skewness menunjukkan angka di luar rentang -2 dan 2 sehingga pengkategoriannya masih menggunakan standar nilai median masing-masing bagian. Khusus pada bagian otonomi dan peran perawat, pengkategorian citra positif dan negatif menggunakan standar nilai mean. Hal ini karena pada bagian otonomi dan peran perawat distribusi datanya normal.

Tabel 4. Distribusi Frekuensi Responden berdasarkan Persepsi terhadap Bagian Citra Profesi Perawat $(n=329)$

\begin{tabular}{lccccc}
\hline \multicolumn{2}{l}{$\begin{array}{l}\text { Bagian citra } \\
\text { (n) } \quad(\%)\end{array} \quad(\mathrm{n})$} & $(\%)$ & & & \\
\hline Sikap perawat & & 277 & 84,2 & 52 & 15,8 \\
Perilaku perawat & 166 & 50,5 & 163 & 49,5 \\
Kinerja perawat & & 173 & 52,6 & 156 & 47,4 \\
$\begin{array}{l}\text { Profesi dan pelayanan } \\
\text { keperawatan }\end{array}$ & 191 & 58,1 & 138 & 41,9 \\
Otonomi dan peran perawat & 160 & 48,6 & 169 & 51,4
\end{tabular}

Sumber Data : Primer (2016)

Berdasarkan Tabel 4, diketahui bahwa lebih dari 50\% mahasiswa mempersepsikan tiap bagian citra profesi perawat secara positif. Pada bagian sikap perawat kebanyakan mahasiswa mempersepsikan citra positif $(84,2 \%)$. Namun demikian, pada bagian otonomi dan peran perawat sejumlah $51,4 \%$ mahasiswa mempersepsikan citra negatif. Terkait dengan bagian otonomi dan peran perawat ini sebanyak $27,6 \%$ mahasiswa tidak menyetujui pernyataan dalam kuesioner bahwa kolaborasi antara perawat dan tenaga kesehatan lain sudah jelas.
Pada pernyataan terbuka yang terdapat di akhir kuesioner, mayoritas responden menyatakan bahwa profesi perawat sudah cukup baik, namun dalam pelayanannya perlu ditingkatkan lagi. Sebagian responden masih menganggap profesi perawat sebagai asisten dokter dengan peran yang tumpang tindih antara perawat dan tenaga kesehatan lain. Mengenai peran kolaborasi antara perawat dengan apoteker, sebagian besar responden menyatakan peran tersebut belum terlihat/terjalin. 


\section{DISKUSI}

Hasil penelitian seperti ditunjukkan pada Tabel 3 sebanyak $57,4 \%$ responden mempersepsikan citra profesi perawat sebagai hal yang positif. Hasil dari penelitian ini sesuai dengan penelitian Seago et al. (2006) yang menyatakan mahasiswa secara umum memiliki persepsi positif terhadap keperawatan sebagai sebuah profesi. Penelitian Wilbur \& Kelly (2015) menyatakan kedua grup mahasiswa farmasi (junior dan senior) memberikan sikap positif terhadap kontribusi perawat dalam perawatan pasien.

Responden dalam penelitian ini memiliki pengetahuan dan pengalaman berinteraksi dengan perawat, sebagai pasien yang dirawat ataupun kerabat perawat. Pengalaman ini bisa jadi baik sehingga secara umum persepsi yang terbentuk oleh responden adalah citra profesi perawat yang positif.

Citra profesi perawat yang dipersepsikan positif ini dapat dipengaruhi oleh beberapa faktor. Berdasar penelitian Cohen (2008) terdapat beberapa faktor yang memengaruhi citra perawat yakni cara perawat mempresentasikan diri di depan pasien dan keluarga, cara berpakaian, ketrampilan yang ditunjukkan perawat, penampilan perawat saat bersama tenaga kesehatan lain, dan tingkah laku perawat di area kerja.

Pada Tabel 4, digambarkan citra profesi perawat dalam bagian-bagian yang lebih spesifik. Bagian citra sikap perawat menunjukkan hasil citra positif sebanyak $84,2 \%$. Namun, sejumlah 52 mahasiswa memiliki persepsi citra yang negatif. Salah satunya pada pernyataan sikap perawat yang ramah dan tidak judes sebanyak $14,3 \%$ responden memilih opsi tidak setuju. Pada pernyataan terbuka responden juga menyampaikan mengenai sikap perawat yang kurang berempati pada pasien dan beberapa bersikap tidak adil dalam memberikan pelayanan. Pada penelitian Wilbur \& Kelly (2015) mahasiswa farmasi senior menganggap perawat sebagai sarana untuk berkomunikasi dan memperoleh informasi pasien, namun beberapa mahasiswa menilai bahwa perawat kurang mampu untuk menginformasikan data pasien pada tim kesehatan lain.

Pada penelitian Kusumaningsih (2009), masyarakat merasa puas dengan sikap perawat yang berespon terhadap kebutuhan pasien tetapi tidak puas dengan ketidakramahan perawat. Meskipun responden penelitian menilai sikap yang ditunjukkan oleh perawat baik, responden masih melihat perawat kurang melakukan komunikasi yang terapeutik.

Pada penelitian ini, setengah dari responden menyatakan bagian citra perilaku perawat positif dan setengahnya menyatakan negatif. Responden menilai perawat kurang melakukan penyuluhan di lingkungan sekitarnya dan kurang memberikan informasi pada pasien dan keluarga. Di bagian pernyataan terbuka responden menambahkan bahwa terkadang perawat kurang cekatan dan ragu dalam bertindak. Hasil ini sedikit berbeda dengan penelitian Desiana (2012) yang mendapatkan persepsi positif terhadap perilaku perawat $(67 \%)$. Hasil ini dapat dipengaruhi oleh karakteristik usia dan pendidikan responden yang berbeda. Sebagian responden dalam penelitian juga tidak memiliki pengalaman dirawat di rumah sakit ataupun berhubungan kerabat dengan perawat sehingga persepsi yang muncul mungkin didasarkan pada informasi yang didapat sepintas.

Pada bagian citra kinerja perawat dipersepsikan dengan positif oleh 52,6\% responden. Meski citra kinerja perawat dipersepsikan dengan positif, sebagian responden menilai bahwa perawat belum 
melakukan diskusi terapi obat dengan dokter dan apoteker. Hal ini didukung dengan pernyataan terbuka responden bahwa kolaborasi antara perawat, dokter, dan apoteker belum terjalin dalam diskusi obat. Hal yang sama dilaporkan pada penelitian Wilbur \& Kelly (2015) yang menunjukkan bahwa terdapat pernyataan dari mahasiswa farmasi yang menyatakan bahwa peran farmasi klinis saat ini belum diterapkan dan perawat masih berperan dalam pemberian obat serta konseling penggunaan obat yang semestinya dilakukan oleh farmasis. Mahasiswa farmasi menganggap hal ini sebagai peran yang tumpang tindih. Menurut Wiedenmayer et al. (2006) seiring dengan perubahan fokus pelayanan kesehatan pada pasien, peran apoteker yang semula hanya meracik obat dan menyuplai sediaan farmasi kini berubah menjadi pemberi pelayanan dan informasi.

Jika dilihat berdasarkan aturan yang ada, apoteker berkewajiban untuk menyerahkan obat langsung kepada pasien (Peraturan Pemerintah No. 51 tahun 2009). Pada penelitian Herman, Handayani \& Siahaan (2013), apoteker bersama dengan dokter dan perawat menjadi bagian dari Komite Farmasi atau Terapi yang bertugas menetapkan formularium. Namun, di beberapa rumah sakit fokus pekerjaan apoteker terbagi pada administrasi dan jumlah sumber dayanya kurang mencukupi sehingga perawat masih melaksanakan pemberian obat. Sementara itu dalam Undang-Undang No. 38 tahun 2014 tentang Keperawatan disebutkan bahwa perawat dalam menjalankan tugas sebagai pemberi asuhan keperawatan juga berwenang untuk melakukan penatalaksanaan pemberian obat kepada klien sesuai dengan resep tenaga medis atau obat bebas dan obat bebas terbatas.

Hasil persepsi responden terhadap citra profesi dan pelayanan keperawatan menunjukkan positif. Sebanyak $84,8 \%$ responden menyetujui pernyataan profesi perawat sebagai fokus dari pengobatan kesembuhan pasien. Namun, beberapa responden menyatakan bahwa profesi perawat masih dinilai rendah dibandingkan profesi kesehatan lain, sementara pelayanan perawat lebih banyak diberikan selama 24 jam.

Penelitian Thompson et al. (2011) melaporkan bahwa masyarakat mengagumi dan menghormati pekerjaan perawat yang memberikan perawatan dengan baik serta jam kerja yang panjang. Namun, masyarakat merasa perawat memiliki status yang rendah dan kurang memiliki kualifikasi. Serupa dengan hasil penelitian Wilbur \& Kelly (2015) mahasiswa farmasi secara konsisten menyatakan respek terhadap kedekatan perawat dengan pasien, tetapi kurang menganggap pengetahuan dan kontribusi perawatan lainnya.

Kondisi seperti disebutkan di atas dapat terjadi karena kebanyakan orang kurang mengetahui tentang tingkat pendidikan perawat, jenjang karier, dan spesialisasi profesi perawat (Morris, Jones \& Hunt, 2010). Masyarakat menilai semua orang dapat menjadi perawat jika berkeinginan. Pekerjaan perawat juga dianggap sekedar memberikan bantuan pada pasien sehingga dapat melakukan aktivitas kesehariannya.

Hasil dari citra otonomi dan peran perawat pada penelitian ini cenderung dipersepsikan negatif oleh responden. Penelitian Seago et al. (2006) menunjukkan hal yang sama bahwa mahasiswa memandang kurang baik terhadap kesempatan perawat untuk bekerja mandiri (independent). Pada penelitan Cook \& Stoecker (2014) didapatkan dua penelitian dengan hasil mahasiswa kesehatan memberikan peringkat tertinggi pada kerja tim perawat dan peringkat terendah pada kemandirian perawat. Citra perawat yang 
negatif lebih dipengaruhi oleh adanya mitos, miskonsepsi, dan mispersepsi masyarakat (Thompson et al., 2011).

Responden penelitian yang merupakan mahasiswa farmasi sebenarnya telah dikenalkan dengan program IPE (Interprofessional Education) yang mengembangkan nilai kolaborasi antar profesi. Adanya program IPE memberikan dampak positif pada pengetahuan, pemahaman, sikap, persepsi, keterampilan, dan kepercayaan mahasiswa terhadap peran profesional antar profesi dan kerja tim kesehatan (The Impact and Effectiveness of Inter-Professional Education in Primary Care, 2006). Namun demikian, masih adanya persepsi negatif mahasiswa farmasi terhadap citra perawat perlu menjadi perhatian semua pihak, khususnya dalam implementasi IPE pada tahap akademik bahwa peran, fungsi, dan kewenangan profesi (perawat dan farmasi) perlu dilaksanakan secara kolaborasi interprofessional (Ardinata, KarotaBukit, Arrum, 2017). Menurut penelitian Sedyowinarso et al. (2011) masih terdapat hal-hal yang menghambat pelaksanaan IPE diantaranya ego masing-masing profesi, keberagaman birokrasi dan kurikulum di institusi pendidikan profesi kesehatan, fasilitas fisik dan konsep pembelajaran yang belum jelas, serta kekaburan identitas dan peran masing-masing profesi.

Penelitian ini merupakan penelitian kuantitatif dengan menggunakan kuesioner dan pernyataan terbuka sehingga tidak mencakup opini responden secara mendalam seperti halnya penelitian kualitatif. Penelitian ini juga terbatas hanya menggambarkan persepsi mahasiswa farmasi terhadap citra profesi perawat bukan gambaran citra profesi perawat dari banyak mahasiswa kesehatan yang lain. Pada pengambilan sampel secara purposive tidak menggunakan stratifikasi sehingga responden mahasiswa tiap angkatan tidak terwakili secara proporsional.

\section{SIMPULAN}

Berdasarkan hasil penelitian dan pembahasan dapat disimpulkan bahwa citra profesi perawat yang dipersepsikan mahasiswa farmasi tergolong dalam kategori positif. Namun, otonomi/kemandirian perawat masih dinilai rendah dan peran kolaborasi dengan tenaga kesehatan lain masih kurang maksimal dan terjadi tumpang tindih.

Responden dalam penelitian yang merupakan mahasiswa farmasi memberikan respek terhadap profesi perawat yang akan menjadi sejawat dalam tim kesehatan nantinya tetapi responden masih belum memahami dengan jelas peran dari profesi perawat secara mandiri. Sehingga perawat dalam pendidikannya dapat memulai kolaborasi antar profesi kesehatan untuk meningkatkan citra profesi perawat dan mengenalkan pendidikan keperawatan pada profesi kesehatan lain. Perawat perlu untuk meningkatkan peran mandiri dan kolaborasi serta semakin menunjukkan profesionalitas agar dapat membangun citra baik di lingkungan kerja dan masyarakat.

\section{DAFTAR PUSTAKA}

American College of Clinical Pharmacy (ACCP) White Paper. (2009). Interprofessional education: principles and application. A framework for clinical pharmacy. Pharmacotherapy, 29: 146164.

Ardinata, D., Karota-Bukit, E., Arrum, D. (2017). Student perception of interprofessional education application at the Health Sciences University of Sumatera Utara. Enfermeria Clinica, 2017;27(Suppl. Part I): 236-239.

Cohen, S. (2008). Reflection on the image of nursing. SNM Benchmarking Report. 
Retrieved from http://www.hcpro.com/ content/222604.pdf

Cook, K. \& Stoecker, J. (2014). Healthcare student stereotypes: A systematic review with implications for interprofessional collaboration. Journal of Research in Interprofessional Practice and Education, 4(2): 1-13.

Desiana, R. I. (2012). Hubungan antara persepsi pelajar SMA kelas XII di SMAN 1 Cibinong tentang profesi perawat dengan minat melanjutkan pendidikan di bidang keperawatan (Skripsi). Fakultas IImu Keperawatan Universitas Indonesia, Jakarta, Indonesia.

Direktorat Jenderal Pendidikan Tinggi Kementerian Pendidikan dan Kebudayaan. (2014). Penguatan nilai kolaborasi antar profesi dan pengembangan pendidikan interprofesi menuju pelayanan kesehatan yang berkualitas. Dalam Simposium Interprofessional Education (IPE), 29 Oktober 2014. Retrieved from http:// med.unhas.ac.id/event/ipemakassar/ materi/Speaker/IPE\%20untuk\%20 peningkatan $\% 20$ kualitas $\% 20$ kesehatan\%20Dikti\%2029\%20okt\%20 rev.pdf

Handoyo, Kamaluddin, R., \& Ekowati, W. (2006). The perception of senior high school students in Banyumas District towards profession and education of nursing bachelor. Jurnal Keperawatan Sudirman, 1(1): 6-14.

Herman, M. J., Handayani, R. S., \& Siahaan, S. A. (2013). Kajian praktik kefarmasian apoteker pada tatanan rumah sakit. Jurnal Kesehatan Masyarakat Nasional, 7(8): 365-372.

Kementerian Kesehatan Republik Indonesia. (2014). Profil Kesehatan Indonesia Tahun 2013. Jakarta: Kementerian Kesehatan.
Kusumaningsih, I. (2009). Persepsi masyarakat terhadap citra perawat di Balkesmas Sint Carolus Kelurahan Paseban Jakarta Pusat Tahun 2009 (tesis). Fakultas IImu Keperawatan Universitas Indonesia, Jakarta, Indonesia.

Meiring, A. \& Wyk, van N., C. (2013). The image of nurses and nursing as perceived by The South African Public. Africa Journal of Nursing and Midwifery, 15(2): 3-15.

Morris, V., Jones, R., \& Hunt, A. (2010). Nursing and nurses: The image and the reality. Nursing Management, 17(1): 1619.

Peraturan Pemerintah Nomor 51 Tahun 2009 tentang Pekerjaan Kefarmasian. Retrieved from https://www.persi.or.id/ images/regulasi/pp/pp512009.pdf

Samaniego, V. C. \& Carcamo, S. (2013). the nursing image and professional identity: The future of a construction. Invest Educ Enferm, 31(1): 54-62.

Seago, J. A., Spetz, J., Alvarado, A., Keane, D., Grumbach, K. (2006). The nursing shortage: Is it really about image? Journal of Healthcare Management, 51(2): 96-108.

Sedyowinarso, M., Fauziah, F. A., Aryakhiyati, N., Julica, M. P., Munira, L., Sulistyowati, E., Masriati, F. N., ..., Piscesa, S. (2011). Persepsi mahasiswa dan dosen pendidik terhadap model pembelajaran Interprofessional Education (IPE). Kajian Nasional Mahasiswa IImu Kesehatam Indonesia. Jakarta: HPEQ Project.

Sudarma, M. (2008). Sosiologi untuk kesehatan. Jakarta: Salemba Medika.

The image of nursing: What It is and How It Needs to Change. (2011). Jones \& Bartlett Learning, LLC. Retrieved from http://samples. jbpub.com/9781449649029/46066 $\mathrm{CHO3}$ 6031.pdf 
The Impact and effectiveness of interprofessional education in primary care. (2006). Retrieved from Royal College of Nursing website: http://www.rcn.org.uk

Thompson, T. M., Shepherd, J., Plata, R., \& Marks.-Maran, D. (2011). Diversity, fullfillment and privilege: the image of nursing. Journal of Nursing Management, 19: 683-692.

Undang-Undang Republik Indonesia Nomor 38 Tahun 2014 tentang Keperawatan. Retrieved from https:// www.kemenkopmk.go.id/sites/default/ files/produkhukum/UU\%20Nomor $\% 20$ 38\%20Tahun\%202014.pdf

Wiedenmayer, K., Summers R. S., Mackie, C. A., Gous, A. G. S., Everard, M., \& Tromp, D. (2006). Developing pharmacy practice a focus on patient care. Netherlands: World Health Organization and International Pharmaceutical Federation.

Wilbur, K. \& Kelly, I. (2015). Interprofessional impressions among nursing and pharmacy students: A qualitative study to inform interprofessional education initiatives. BMC Medical Education, 15(53): 1-8.

Yuda, H. T., Handoyo, \& Asti, A. D. (2010). Perbedaan persepsi tentang profesi perawat pada siswa SMA Kelas XII di Kabupaten Kebumen. Jurnal IImiah Kesehatan Keperawatan, 6(1): 22-29. 